\title{
Investigating the Performance of Ghana's Locally Produced Alcohol (Akpeteshie) in Stripping Gold-Loaded Carbon
}

\author{
Francis Adjei Jarchie ${ }^{1}$, Felix Oppong ${ }^{2}$, Prosper Gyasi ${ }^{3}$, Clement Kwasi Owusu ${ }^{4}$ \\ ${ }^{1,3,4}$ Department of Minerals Engineering, University of Mines and Technology, P.O. Box 237, Tarkwa, \\ Ghana \\ ${ }^{2}$ School of Resource and Environmental Engineering, Wuhan University of Science and Technology, Wuhan \\ 430081, PR China
}

\begin{abstract}
Gold adsorbed unto activated carbon is recovered downstream via various stripping techniques paramount among which are the Zadra elution method and the Anglo American Research Laboratory (AARL) method before final gold recovery by electrowinning. These conventional stripping systems require a relatively higher temperature and longer elution hours. These are effective but the relatively longer extraction times that accompany them have been a major concern over the years. This has encouraged diverse research operations to ascertain an alternative method of elution that would render the process more economical. One research finding that has been very successful in reducing the extraction time significantly is alcohol stripping. Laboratory produced ethanol, methanol, isopropanol, and ethylene glycol have all proven to be effective in stripping gold from loaded carbon at elevated temperatures. One main hindrance to the usage of this method at the commercial scale is the relatively higher cost of ethanol among other operational and environmental challenges. This work investigates the performance of Ghana's locally produced alcohol (akpeteshie) in stripping of gold from gold-loaded carbon at lower temperatures with the aim of finding an alternative method for gold stripping which might be cheaper than conventional systems. Cost analysis conducted revealed that akpeteshie is relatively cheaper than laboratory-produced ethanol. This was one of the key motivations of the research work. A range of different strip solutions were used (hydro-ethanol, caustic solution and lastly caustic and ethanol mixture). The experimental work was carried out at the laboratory scale, using gold-loaded carbon at room temperature and at 60 and $70{ }^{\circ} \mathrm{C}$ temperatures respectively and up to $8 \mathrm{~h}$ extraction time. Hydro-ethanol was the most rapid eluant with $66 \%$ Au eluted after $8 \mathrm{~h}$ at $70{ }^{\circ} \mathrm{C}$, followed by the ethanol and caustic mixture which yielded $42 \%$ extraction after $8 \mathrm{~h}$. Caustic was the least effective with $8 \mathrm{~h}$ required for a $20 \%$ extraction yield. Interestingly, $92 \%$ A u extraction was obtained at $70^{\circ} \mathrm{C}$ when hydro-ethanol was used as an eluant to strip fine carbon.
\end{abstract}

Keywords: Akpeteshie, Eluant (Strip Solution), Extraction Time, Gold-Loaded Carbon, Fine Carbons.

\section{INTRODUCTION}

Gold dissolved into solution during cyanidation can be recovered by precipitation using zinc powder in the Merrill-Crowe process or by adsorption unto activated carbon [1-4]. Precious metals such as Au and Ag adsorbed unto activated carbon are extracted downstream using various technologies such as hot elution or pressure desorption with hydro-alcoholic solutions before final recovery by electrochemical methods [5,6,4]. Conventional stripping systems involve the use of relatively high temperatures of around $90-120{ }^{\circ} \mathrm{C}$ and longer elution times ranging from 12-72 $\mathrm{h} \mathrm{[7-13].} \mathrm{Another} \mathrm{method} \mathrm{that} \mathrm{is} \mathrm{also} \mathrm{in} \mathrm{use} \mathrm{is} \mathrm{the} \mathrm{micron} \mathrm{elution}$ method [11]. The micron elution method involves soaking the gold-loaded carbon in a solution of caustic cyanide followed by elution with acetonitrile, ethanol or methanol vapour between 65 and $80{ }^{\circ} \mathrm{C}$. Elution is usually completed within 4 to 6 hours [14,11].

In this project, the efficiency of Ghana's locally produced alcohol (akpeteshie) in stripping gold from loaded activated carbon was investigated, with the aim of finding an alternative method for gold stripping, which might be cheaper than the conventional 
systems. Essentially, the effects of extraction time and temperature on gold desorption rate was investigated using different eluants (caustic, hydro-ethanol \& ethanol and caustic mixture).

\section{EXPERIMENTAL APPROACH}

\subsection{Experimental Criteria}

Stripping of gold from the loaded activated carbon was carried out using the following analytical grade reagents; ethanol, sodium hydroxide (caustic) and deionized water. The gold-loaded carbon was obtained from a mining company in Tarkwa and it had a gold loading of $530 \mathrm{mg} / \mathrm{L}$. Extraction tests were conducted on a hot plate containing $4 \mathrm{~g}$ of carbon in $100 \mathrm{~mL}$ of strip solution for 8 hours. $10 \mathrm{~mL}$ solution samples were withdrawn at designated time intervals during the process for AAS analysis.

All desorption tests were conducted using the following experimental conditions: temperature: $60-70{ }^{\circ} \mathrm{C} ; 8 \mathrm{~h}$ extraction time; $\mathrm{pH}$ 12. Preliminary tests verified that the presence of caustic in the alcohol stripping process was needful for effective extraction.

The stripping solutions used were water containing $20 \% \mathrm{v} / \mathrm{v}$ of ethanol, $1 \% \mathrm{w} / \mathrm{v}$ of NaOH, a solution mixture of $20 \% \mathrm{v} / \mathrm{v}$ ethanol and caustic, $1 \%$ by weight caustic, cyanide was not used. The experimental error was estimated as $5 \%$ by replicated tests.

\subsection{Test Procedure}

- $4 \mathrm{~g}$ of gold-loaded carbon sample was treated with $100 \mathrm{~mL}$ of strip solution in each experiment. The solution compositions were however varied accordingly with respect to the experimental criteria discussed above.

- $\quad$ The natural $\mathrm{pH}$ of the alcohol used was 5 and it was adjusted to 12 using $\mathrm{NaOH}$ pellets. However, other set of control experiments were carried out without altering the $\mathrm{pH}$ of the alcohol.

- $\quad$ The experiment was carried out for 8 hours using hot plate as a heat source. However, the set of experiment that was carried out at room temperature was allowed a time of 24 hours.

- $\quad$ The required temperature for each set of experiment was regulated and maintained.

- $\quad 10 \mathrm{~mL}$ solution samples were taken at designated time intervals of 1, 2, 4, 6 and 8 hours for AAS analyses to estimate the gold desorbed into solution.

- $\quad$ The gold desorbed into solution at these time intervals were thus read and recorded.

- $\quad$ Each set of experiment was repeated once and the mean of the results was recorded.

Fig. 1 below shows the experimental set-up.

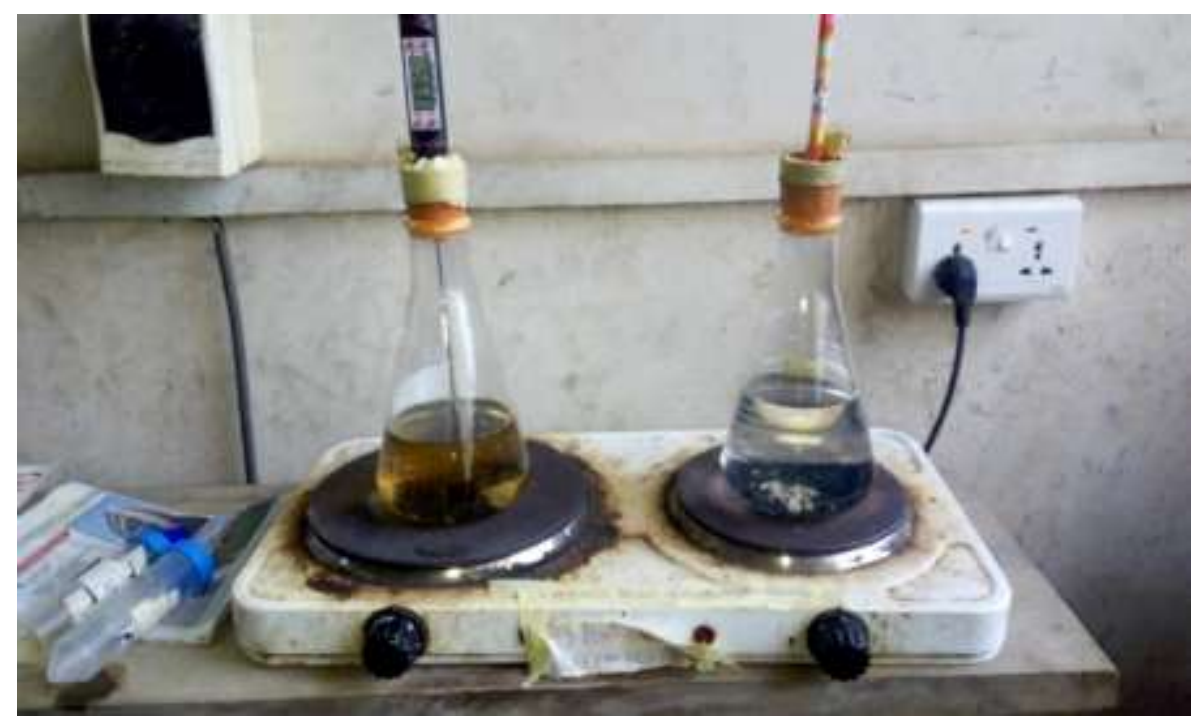

Fig. 1: Experimental Set up

Table 1 shows the values of gold desorbed into solution at temperatures of 60 and $70{ }^{\circ} \mathrm{C}$ with time. The carbon was treated with the three strip solutions considered. 
International Journal of Advances in Scientific Research and Engineering (ijasre), Vol 6 (3), March -2020

Table 1: Gold Desorption Using Hydro-Alcohol at Unaltered pH of 5

\begin{tabular}{|c|c|c|}
\hline & \multicolumn{2}{|c|}{$\begin{array}{c}\text { Gold Desorbed into Solution (ppm) with } \\
\text { temperature }\end{array}$} \\
\hline & $60^{\circ} \mathrm{C}$ & $70^{\circ} \mathrm{C}$ \\
\hline 0 & 0.0 & 0.0 \\
\hline 1 & 0.0 & 0.1 \\
\hline 2 & 0.1 & 0.3 \\
\hline 4 & 0.2 & 0.3 \\
\hline 6 & 0.3 & 0.4 \\
\hline 8 & 0.3 & 0.5 \\
\hline
\end{tabular}

Table 2 shows the values of gold that was stripped into solution at temperatures of $60{ }^{\circ} \mathrm{C}$ from carbon. The carbon was treated with the three strip solutions considered.

Table 2: Gold desorbed into solution at $60{ }^{\circ} \mathrm{C}$ temperature with time

\begin{tabular}{|c|c|c|c|}
\hline \multicolumn{4}{|c|}{ Gold Desorbed into Solution (ppm) with time } \\
\hline Time $(\mathrm{h})$ & $\begin{array}{c}\mathrm{NaOH}+ \\
\text { Alcohol }\end{array}$ & Alcohol & $\mathrm{NaOH}$ \\
\hline 0 & 0.00 & 0.000 & 0.000 \\
\hline 1 & 5.62 & 13.16 & 1.55 \\
\hline 2 & 12.97 & 26.02 & 2.57 \\
\hline 4 & 24.65 & 37.64 & 4.99 \\
\hline 6 & 26.91 & 40.14 & 9.94 \\
\hline 8 & 30.07 & 45.68 & 12.31 \\
\hline
\end{tabular}

Table 3 below shows the values of gold that was stripped into solution at temperatures of $70{ }^{\circ} \mathrm{C}$ from carbon. The carbon was treated with the three strip solutions considered.

Table 3: Gold desorbed into solution at $70^{\circ} \mathrm{C}$ temperature with time

\begin{tabular}{|c|c|c|c|}
\hline \multicolumn{4}{|c|}{ Gold Desorbed into Solution (ppm) with time } \\
\hline Time $(\mathrm{h})$ & $\begin{array}{c}\mathrm{NaOH}+ \\
\text { Alcohol }\end{array}$ & Alcohol & $\mathrm{NaOH}$ \\
\hline 0 & 0.00 & 0.00 & 0.00 \\
\hline 1 & 12.02 & 19.71 & 2.52 \\
\hline 2 & 28.16 & 37.61 & 4.72 \\
\hline 4 & 34.30 & 51.06 & 6.95 \\
\hline 6 & 38.62 & 59.85 & 13.41 \\
\hline 8 & 42.43 & 66.44 & 20.13 \\
\hline
\end{tabular}

Table 4 below shows the values of gold that was stripped into solution from carbon at room temperature. The carbon was treated with the three strip solutions considered. 
International Journal of Advances in Scientific Research and Engineering (ijasre), Vol 6 (3), March -2020

Table 4: Gold Desorbed into Solution at Room Temperature with Time

\begin{tabular}{|c|c|c|c|}
\hline \multicolumn{4}{|c|}{ Gold Desorbed into Solution (ppm) with Time } \\
\hline Time $(\mathrm{h})$ & $\mathrm{NaOH}+$ Alcohol & Alcohol & $\mathrm{NaOH}$ \\
\hline 0 & 0 & 0 & 0 \\
\hline 1 & 2.2 & 3.09 & 0 \\
\hline 2 & 2.6 & 6.5 & 0 \\
\hline 4 & 2.79 & 8.88 & 0 \\
\hline 8 & 2.96 & 12.73 & 0 \\
\hline 12 & 6.46 & 15.76 & 0 \\
\hline 24 & 9.47 & 21.13 & 0 \\
\hline
\end{tabular}

Table 5 below shows the results obtained from stripping fine carbon at $60{ }^{\circ} \mathrm{C}$. The carbon was treated with the three strip solutions considered.

Table 5: Gold desorbed into solution at $60^{\circ} \mathrm{C}$ temperature with time

\begin{tabular}{|c|c|c|c|}
\hline \multicolumn{4}{|c|}{ Gold Desorbed into Solution (ppm) with time } \\
\hline Time (h) & $\mathrm{NaOH}+$ Alcohol & Alcohol & $\mathrm{NaOH}$ \\
\hline 0 & 0.00 & 0.00 & 0.00 \\
\hline 1 & 7.93 & 16.12 & 2.62 \\
\hline 2 & 17.53 & 29.65 & 5.11 \\
\hline 4 & 26.91 & 40.07 & 10.20 \\
\hline 6 & 30.26 & 46.59 & 11.76 \\
\hline 8 & 35.22 & 51.54 & 16.95 \\
\hline
\end{tabular}

Table 6 below shows the results obtained from stripping fine carbon at $70{ }^{\circ} \mathrm{C}$. The carbon was treated with the three strip solutions considered.

Table 6: Gold desorbed into solution at $70^{\circ} \mathrm{C}$ temperature with time

\begin{tabular}{|c|c|c|c|}
\hline \multicolumn{4}{|c|}{ Gold Desorbed into Solution (ppm) with time } \\
\hline Time (h) & $\begin{array}{c}\text { NaOH }+ \\
\text { Alcohol }\end{array}$ & Alcohol & NaOH \\
\hline 0 & 0.00 & 0.00 & 0.00 \\
\hline 1 & 18.17 & 29.17 & 2.77 \\
\hline 2 & 32.87 & 46.96 & 9.37 \\
\hline 4 & 43.87 & 58.89 & 14.39 \\
\hline 6 & 53.51 & 81.99 & 21.26 \\
\hline 8 & 57.49 & 92.11 & 26.26 \\
\hline
\end{tabular}




\section{RESULTS AND DISCUSSION}

\subsection{The Effect of $\mathrm{pH}$ on Gold Stripping}

Preliminary experiments conducted at the natural $\mathrm{pH}$ of the alcohol ( $\mathrm{pH}$ of 5) showed low gold extraction. The minimal elution observed may be due to the low $\mathrm{pH}$ of the locally produced alcohol. According to [3], the chemical and physical factors that boost elution hinders adsorption and vice versa. High $\mathrm{pH}$ is a requirement for good elution since elution is essentially the reverse of the adsorption process. Essentially, adsorption of gold unto activated carbon is at its maximum at a $\mathrm{pH}$ range of $4-7$ but the selectivity of the carbon for gold appears to increase with increasing $\mathrm{pH}$ to regions above 10. That is why carbon adsorption (cyanidation) is done at a $\mathrm{pH}$ above 10 aside preventing the evolution of $\mathrm{HCN}$ gas which is environmentally unfriendly. The gold adsorbed at a $\mathrm{pH}$ range of $4-7$ is twice as much as that between the $\mathrm{pH}$ ranges of $9-11$ [15]. Therefore, if low pH favours adsorption, then high $\mathrm{pH}$ must necessarily be a requirement for desorption. The gold desorbed into solution after 8 hours was 0.5 $\mathrm{ppm}$ at $\mathrm{pH} 5$.

\subsection{The Effect of Strip Solution and Temperature on Gold Elution}

Figs. 2 and 3 show gold extraction yield as a function of time for the three strip solutions considered at a temperature of 60 and 70 ${ }^{\circ} \mathrm{C}$. The data show a general trend of increasing gold extraction yield with time for the two temperatures considered. Although both temperatures gave similar kinetics, the extraction yield values were higher at $70{ }^{\circ} \mathrm{C}$.

The red curves shown in figs. 2 and 3 demonstrate the trend for the stripping step conducted using hydro-ethanol as eluant. The trend of the process demonstrates that extraction yield improves with increasing the temperature of the strip solution which is consistent with literature [15]. The gold extraction yield was $45.86 \%$ at $60{ }^{\circ} \mathrm{C}$ and $66.44 \%$ at $70{ }^{\circ} \mathrm{C}$ after 8 hours. At the end of the stripping process, gold concentrations in the final solutions were $16.9 \mathrm{mg} / \mathrm{L}$ at $60{ }^{\circ} \mathrm{C}$ and $24.6 \mathrm{mg} / \mathrm{L}$ at $70{ }^{\circ} \mathrm{C}$.

The blue curves shown in figs. 2 and 3 demonstrate the trend for the stripping step conducted using $1 \% \mathrm{w} / \mathrm{v} \mathrm{NaOH}$ as eluant. The curves reveal that the rate of elution increases with temperature of the strip solution. Desorption rate was at each temperature minimal in the stripping method that utilized Zadra strip solution (caustic) than the rest of the stripping techniques. This is because Zadra elution is maximum at relatively high temperatures normally between 110 and $150{ }^{\circ} \mathrm{C}$. Basically, temperatures of around 60 and $70{ }^{\circ} \mathrm{C}$ are relatively lower for significant desorption to be realized from the Zadra method. The gold extraction yield was 12.31 $\%$ at $60{ }^{\circ} \mathrm{C}$ and $20.13 \%$ at $70{ }^{\circ} \mathrm{C}$ after 8 hours. At the end of the stripping process, gold concentrations in the final solutions were $4.6 \mathrm{mg} / \mathrm{L}$ at $60{ }^{\circ} \mathrm{C}$ and $7.5 \mathrm{mg} / \mathrm{L}$ at $70{ }^{\circ} \mathrm{C}$.

The black curve shown in figs. 2 and 3 demonstrates the trend for the stripping step conducted using $20 \% \mathrm{v} / \mathrm{v}$ alcohol and $1 \%$ $\mathrm{w} / \mathrm{v} \mathrm{NaOH}$ as eluant. The curves reveal that the rate of elution increases with temperature of the strip solution. Alcohol improved upon the elution rate of the Zadra. This could be attributed to the fact that there was an add-up desorption contribution from the alcohol. No real reaction has been found chemically to exist between ethanol and $\mathrm{NaOH}$ and as such at every point in time in the stripping process, both $\mathrm{NaOH}$ and ethanol exist in the strip solution and each component effects desorption accordingly. Therefore, the combined effect of these two strip reagents coupled with elevated temperature adds up to enhance or boost the elution rate of the Zadra. The gold extraction yield was $30.07 \%$ at $60{ }^{\circ} \mathrm{C}$ and $42.43 \%$ at $70{ }^{\circ} \mathrm{C}$ after 8 hours. At the end of the stripping process, gold concentrations in the final solutions were $11.16 \mathrm{mg} / \mathrm{L}$ at $60{ }^{\circ} \mathrm{C}$ and $15.74 \mathrm{mg} / \mathrm{L}$ at $70{ }^{\circ} \mathrm{C}$. The influence of temperature on desorption was evident in all the stripping steps conducted which is consistent with literature [16]. 


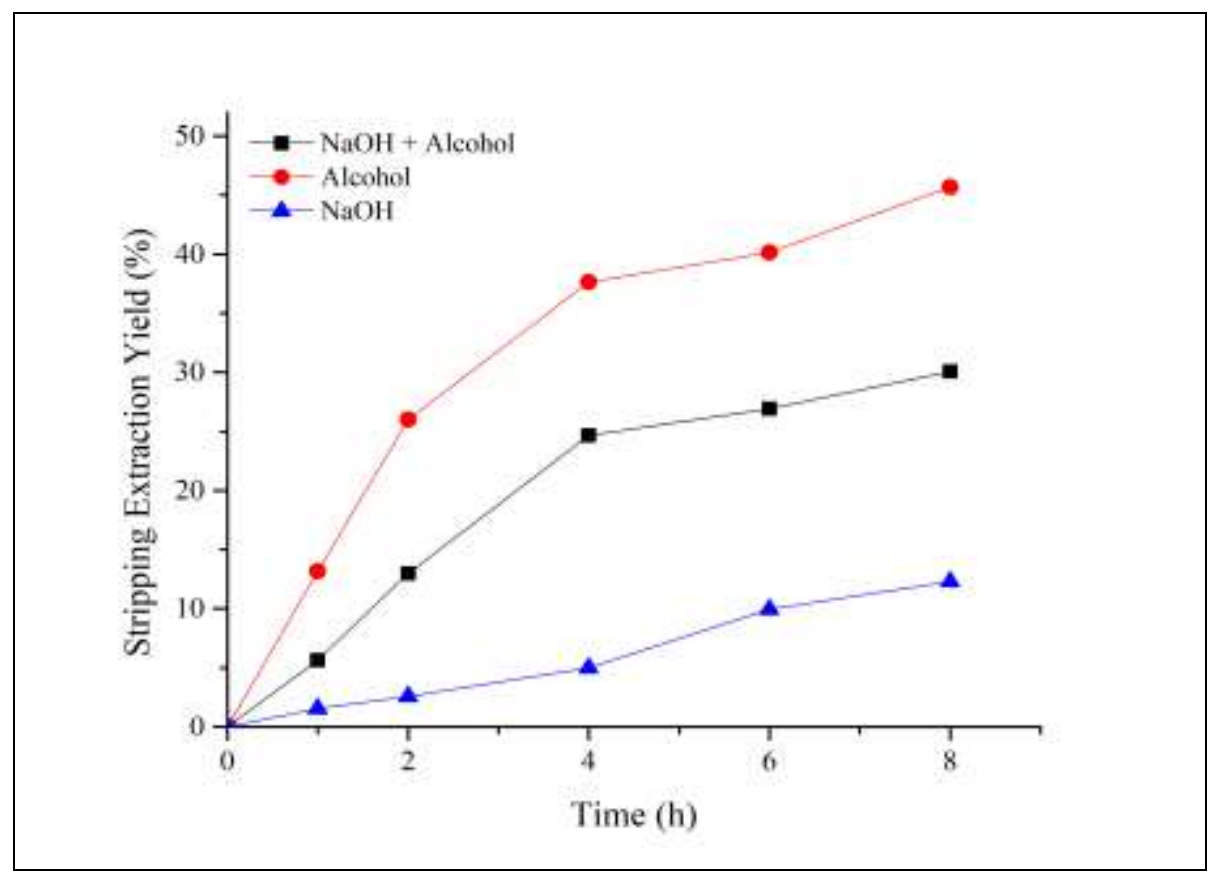

Fig. 2: Gold Stripping Kinetics at $60{ }^{\circ} \mathrm{C}$ Temperature

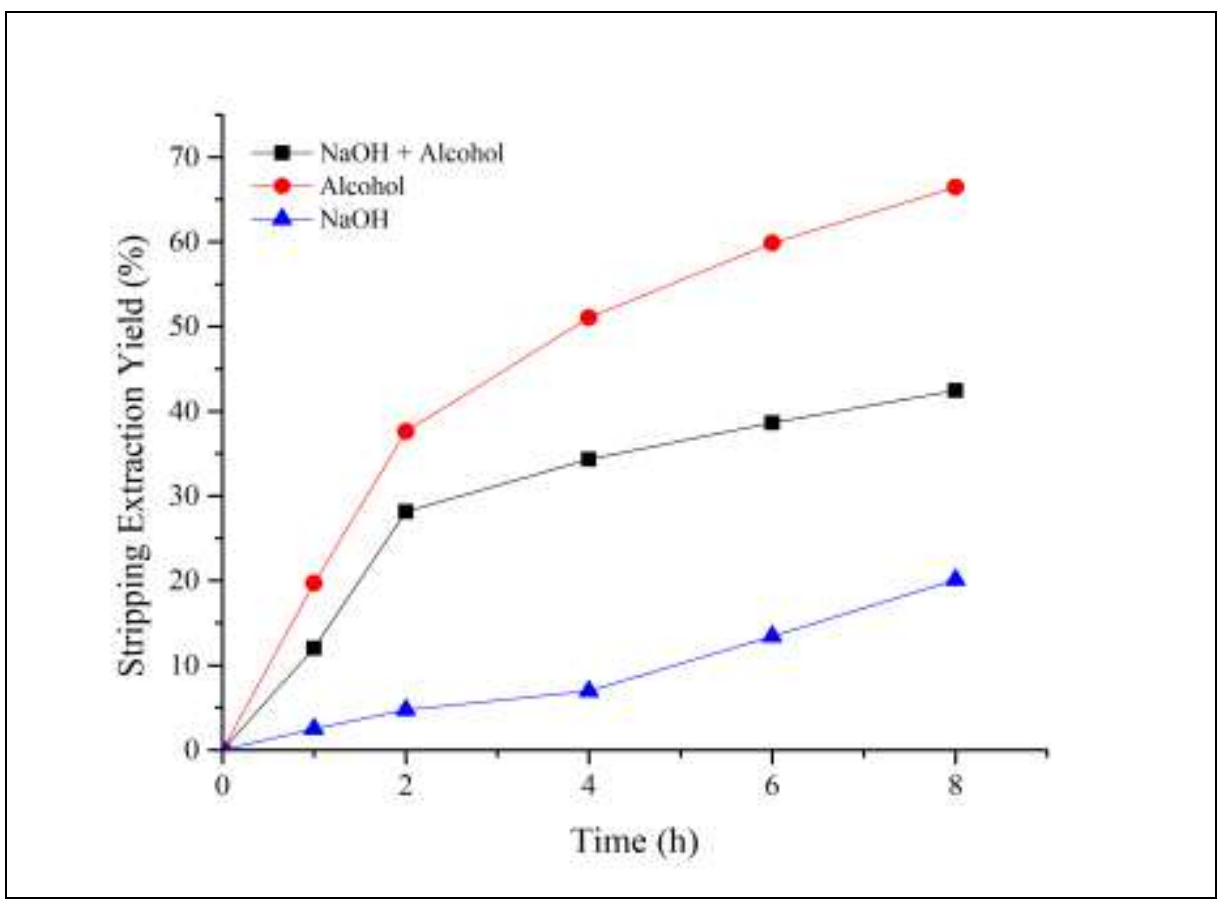

Fig. 3: Gold Stripping Kinetics at $70{ }^{\circ} \mathrm{C}$ Temperature

\subsection{The Effect of Temperature on Elution}

Fig. 4 shows gold extraction yield as a function of time for the three strip solutions considered at room temperature. The data shows a general trend of increasing gold extraction yield with time for the temperature considered except for the caustic solution. Although the strip solutions considered gave low gold extraction yield, the hydro-alcohol gave relatively higher extraction values with time.

The locally manufactured alcohol was able to strip gold from the gold-loaded carbon even at room temperature. The influence of alcohol was as well realised by blending it with caustic solution. The gold extraction yield was $21.13 \%$ for hydro-ethanol and 9.47 $\%$ for the ethanol plus caustic strip solution after 24 hours. At the end of the stripping process, gold concentrations in the final solutions were $7.8 \mathrm{mg} / \mathrm{L}$ for the hydro-ethanol and $3.5 \mathrm{mg} / \mathrm{L}$ for the ethanol plus caustic strip solution. With the caustic solution as eluant, no gold was desorbed into solution at room temperature after 24 hours. 
Fig. 4 clearly indicates the influence of low temperature on elution. According to [15], temperature is the most important parameter that influences elution. The difference in extraction efficiency from the two curves in Fig 4 could be attributed to the fact that ethyl alcohol has a lower surface tension even at room temperature. This property makes ethanol a good strip solution even at room temperature since it is able to overcome the capillary pressures of the carbon to effect gold desorption thereof.

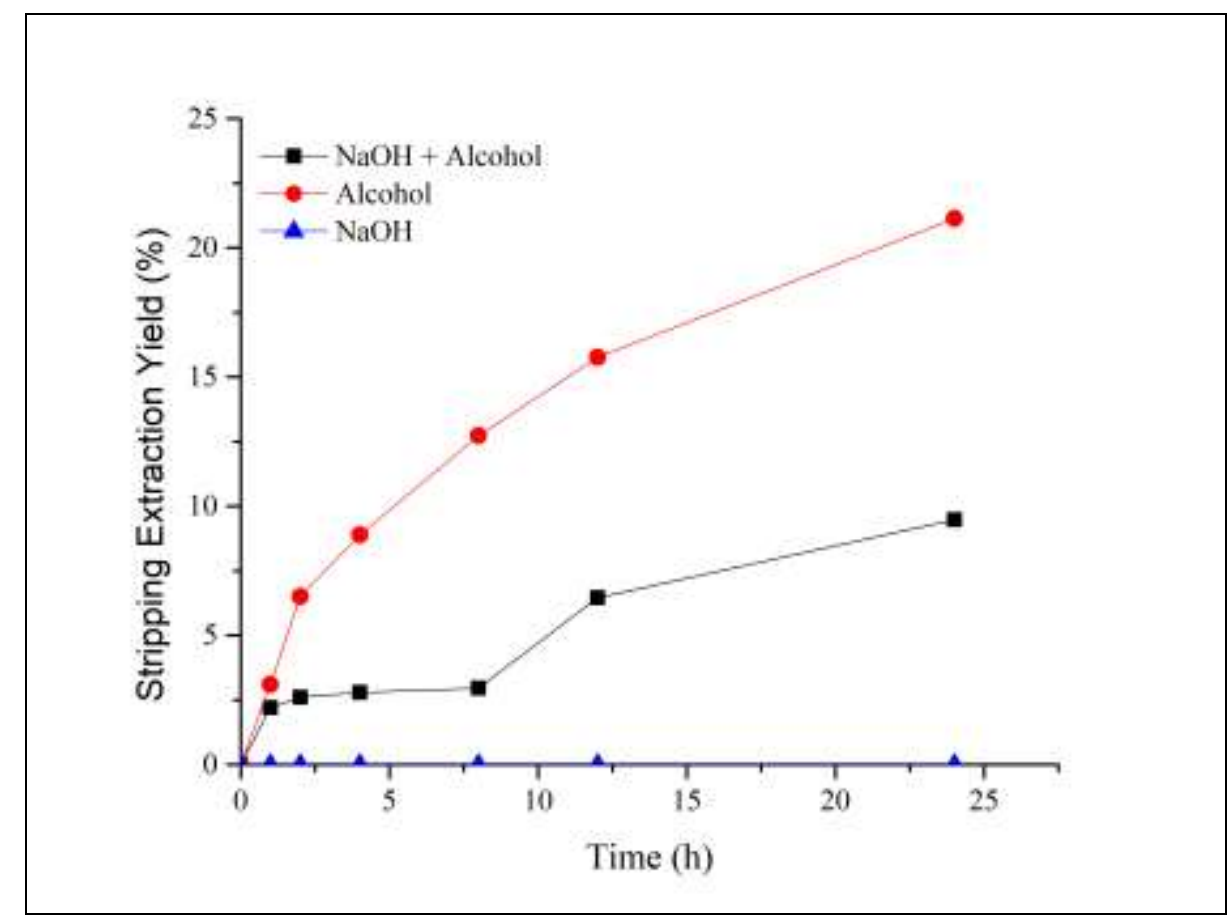

Fig. 4: Gold Stripping Kinetics at Room Temperature

\subsection{The Effect of Carbon Particle Size on Elution}

Figs. 5 and 6 show gold extraction yield as a function of time for the three strip solutions considered at a temperature of 60 and 70 ${ }^{\circ} \mathrm{C}$. Fine carbon was considered in this case. The data show a general trend of increasing gold extraction yield with time for the two temperatures considered. Although both temperatures gave similar kinetics, the extraction yield values were higher at $70{ }^{\circ} \mathrm{C}$.

The red curves shown from figs. 5 and 6 demonstrate the stripping kinetic trend realised using hydro-ethanol as eluant. Interestingly, the trend of the process demonstrates that extraction yield improves with decreasing carbon particle size and increasing the temperature of the strip solution. Gold adsorption unto carbon increases with surface area. Surface area increases with decreasing size. This presupposes that gold adsorption and its subsequent gold loading on the fine carbon might have been higher than that of the coarse carbon. The gold extraction yield was $51.54 \%$ at $60{ }^{\circ} \mathrm{C}$ and $92.11 \%$ at $70{ }^{\circ} \mathrm{C}$ after 8 hours. At the end of the stripping process, gold concentrations in the final solutions were $19.1 \mathrm{mg} / \mathrm{L}$ at $60{ }^{\circ} \mathrm{C}$ and $34.2 \mathrm{mg} / \mathrm{L}$ at $70{ }^{\circ} \mathrm{C}$.

The blue curve shown from figs. 5 and 6 demonstrates the trend for the stripping step conducted using $1 \% \mathrm{w} / \mathrm{v} \mathrm{NaOH}$ as eluant. The curves reveal that the rate of elution increases with temperature of the strip solution. The curves also show that unlike the other stripping techniques, here reduction in particle size of carbon did not improve the extraction rate. Much work has not been done to ascertain the effect of carbon particle size on Zadra elution. However, from figs. 5 and 6, reduction in carbon particle size appears to slow down the Zadra desorption rate and as such that may be the reason why fine carbon is not allowed into the elution columns at the industrial scale. Desorption rate was at each temperature lowest in the Zadra than the rest of the stripping techniques. The gold extraction yield was $16.95 \%$ at $60{ }^{\circ} \mathrm{C}$ and $26.26 \%$ at $70{ }^{\circ} \mathrm{C}$ after 8 hours. At the end of the stripping process, gold concentrations in the final solutions were $6.2 \mathrm{mg} / \mathrm{L}$ at $60{ }^{\circ} \mathrm{C}$ and $9.7 \mathrm{mg} / \mathrm{L}$ at $70{ }^{\circ} \mathrm{C}$.

The black curve shown from figs. 5 and 6 demonstrates the trend for the stripping step conducted using $20 \% \mathrm{v} / \mathrm{v}$ alcohol and $1 \%$ w/v $\mathrm{NaOH}$ as eluant. The curves reveal that the rate of elution increases with increasing temperature of the strip solution and decreasing carbon particle size. Alcohol improved upon the elution rate of the Zadra. This could be attributed to the fact that there was an add-up desorption contribution from the alcohol. The gold extraction yield was $35.22 \%$ at $60{ }^{\circ} \mathrm{C}$ and $57.49 \%$ at $70{ }^{\circ} \mathrm{C}$ after 8 hours. At the end of the stripping process, gold concentrations in the final solutions were $13.1 \mathrm{mg} / \mathrm{L}$ at $60{ }^{\circ} \mathrm{C}$ and $21.3 \mathrm{mg} / \mathrm{L}$ at $70{ }^{\circ} \mathrm{C}$. 


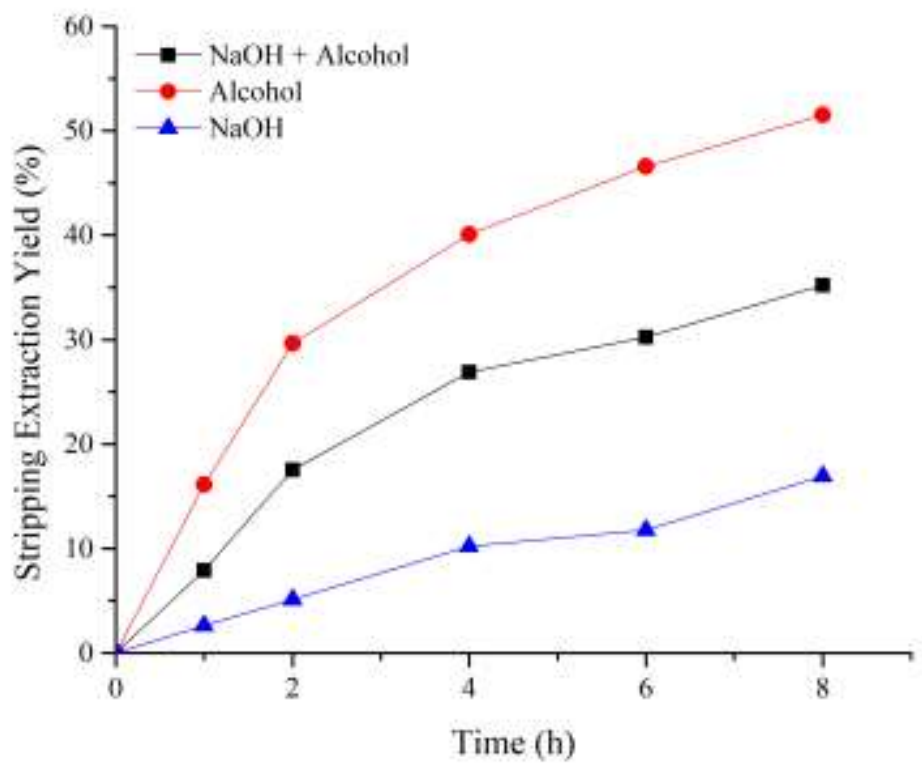

Fig. 5: Gold Stripping Kinetics at $60{ }^{\circ} \mathrm{C}$ Temperature

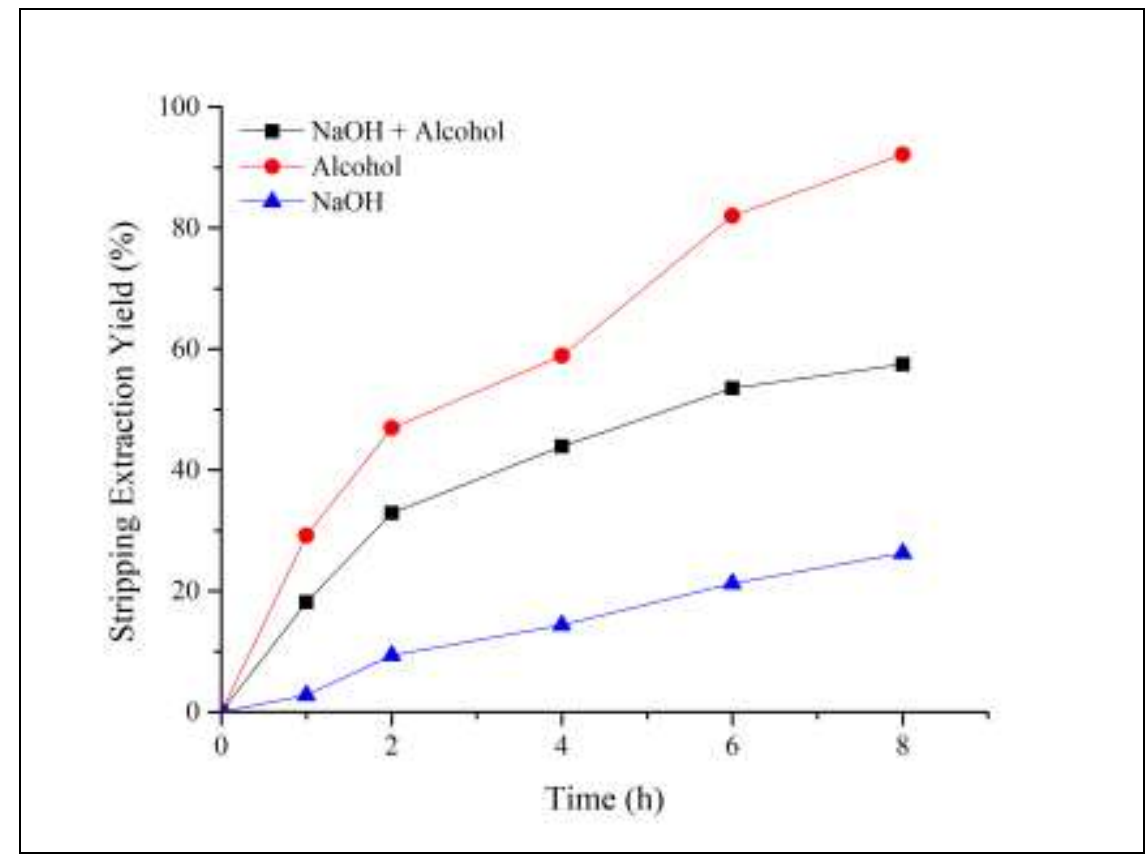

Fig. 6: Gold Stripping Kinetics of Fine Carbon at $70^{\circ} \mathrm{C}$ Temperature

Some school of thought might have concerns about the possible fire hazards associated with alcohol stripping. It is for this very reason the effect of the locally produced alcohol on the conventional Zadra was particularly considered in this work to ascertain the improvement the alcohol can make thereof. Ethanol has a very low flash point even at room temperature. The lower the flash point of a substance the higher its associated fire hazard. Flash point is the minimum temperature at which flames from a volatile substance can burn provided there is an external source of heat. Studies have shown that mixing caustic with ethanol raises the flash point of ethanol significantly. Therefore, the fire hazards associated with elution using the locally produced alcohol and caustic mixture as strip solution would be quite minimal.

\section{CONCLUSIONS AND RECOMENDATIONS}

\subsection{Conclusions}

The research work evaluated and ascertained the stripping ability of Ghana's locally produced alcohol on gold-loaded carbon at varying temperatures. 
International Journal of Advances in Scientific Research and Engineering (ijasre), Vol 6 (3), March -2020

- From the results of the research work, Ghana's locally produced alcohol (akpeteshie) can be used as an alternative reagent for alcohol elution.

- The locally produced alcohol (akpeteshie) can be used to improve upon the conventional Zadra method of gold elution.

\subsection{Recommendations}

- Further work should concentrate on raising the temperature beyond $70{ }^{\circ} \mathrm{C}$ with respect to stripping using Caustic and akpeteshie mixture as eluant.

- Modern research should explore inventing a heat source that can yield fixed temperature upon variation.

- Further work can be done to ascertain how effective hydro-alcohol can be in stripping fine carbon.

\section{ACKNOWLEDGEMENTS}

With a deep sense of gratitude, we express our sincere appreciation to Mr Dennis Amankwah (Lab Assistant) at the Minerals Department of the University of Mines and Technology for his selfless service and assistance that contributed to the success of this work.

\section{REFERENCES}

[1] Adams, M.D., McDougall, G.J. and Hancock, R.D. (1987), "Models for the Adsorption of Aurocyanide onto Activated Carbon: Part II. Extraction of Aurocyanide Ion Pairs by Polymeric Adsorbents", Hydrometallurgy 18, 139-154.

[2] McDougall, G.J., Adams, M.D. and Hancock, R.D. (1987), "Models for the Adsorption of Aurocyanide onto Activated Carbon: Part I. Solvent Extraction of Aurocyanide Ion Pairs by 1-pentanol", Hydrometallurgy 18, 125-138.

[3] Adams, M. D. (1990), "The Mechanism of Adsorption of Aurocyanide onto Activated Carbon: 1. Relation between the Effects of Oxygen and Ionic Strength" Science Direct, Volume 25, Issue 2, pp. 184 - 171.

[4] Ubaldini, S., Massidda, R., Vegliò, F. and Beolchiniet, F. (2004), "Gold Stripping by Hydro-Alcoholic Solutions from Activated Carbon: Experimental Results and Data Analysis by a Semi-Empirical Model”, Science Direct, Hydrometallurgy 81, pp. $44-40$.

[5] Muir, D.M., Hinchliffe, W., Tsuchida, N. and Ruane, M. (1985), "Solvent Elution of Gold from C.I.P. Carbon", Hydrometallurgy 14, 47-65.

[6] Espiell, F., Roca, A., Cruells, M. and Núñez, C. (1988), "Gold Desorption from Activated Carbon with Dilute NaOH/Organic Solvent Mixtures", Hydrometallurgy 19, 321-333.

[7] Davidson, R. J. and Duncanson, D. (1977), “The Elution of Gold from Activated Carbon Using Deionized Water”, Journal of the Southern African Institute of Mining and Metallurgy, Volume 77, pp. 261 - 254.

[8] Davidson, R.J., Veronese, V. and Nkosi, M.V. (1979), "The Use of Activated Carbon for the Recovery of Gold and Silver from Gold-Plant Solutions" Journal of the Southern African Institute of Mining and Metallurgy (SAIMM), Volume 79, Issue 10, pp. $297-281$.

[9] Zadra, J. B. (1950), A Process for the Recovery of Gold from Activated Carbon by Leaching and Electrolysis, Report of Investigations No. 4672, U. S. Department of the Bureau of Mines, Washington, DC, 47pp.

[10] Zadra, J. B., Engel, A. L., and Heinen, H. J. (1952), Process for Recovering Gold and Silver from Activated Carbon by Leaching and Electrolysis, Report of Investigations No. 4843, U.S. Department of Bureau of Mines, Washington, DC, 32pp. [11] Amankwah, R. K. (2016), "Hydrometallurgy Applications", Unpublished Bsc Lecture Notes, University of Mines and Technology, Tarkwa, pp. $44-29$.

[12] Buah, W. K. (2015), "Processing of Minerals Found in Ghana", Unpublished BSc Lecture Notes, University of Mines and Technology, Tarkwa, pp. $21-19$.

[13] Marsden, J. O. and House, C. (2006), “The Chemistry of Gold Extraction (2nd edition)", Society for Mining, Metallurgy, and Exploration (SME), Volume 39, Issue 3, pp. 139 - 138.

[14] Bhattacharyya, D. (2013), “Aurodicyanide Desorption from Activated Carbon”, Unpublished MSc Thesis, Department of Metallurgical Engineering, University of Utah, pp. $20-11$.

[15] Deventer J. S. J. V. and Merwe P. F. V. D. (1994), "Factors Affecting the Elution of Gold Cyanide from Activated Carbon", Science Direct, Volume 7, Issue 1, pp. 86 - 71.

[16] Steyn, R. (2010), "Elution and Carbon Reactivation Basics", https://rsteyn.files.wordpress.com/2010/07/elution-and-carbonreactivation-basics.pdf. Accessed: January 11, 2017. 